\title{
(E)-2-Hexenal Can Stimulate Botrytis cinerea Growth in vitro and on Strawberries in vivo during Storage
}

\author{
Elazar Fallik ${ }^{1}$ \\ Agricultural Research Organization, The Volcani Center, Bet Dagan 50250, Israel
}

Douglas D. Archbold, 2 Thomas R. Hamilton-Kemp, Ann M. Clements, and Randy W. Collins
Department of Horticulture and Landscape Architecture, University of Kentucky, Lexington, KY 40546-0091

Margaret M. Barth

Department of Nutrition and Food Science, University of Kentucky, Lexington, KY 40546-0091

ADDITIONAL INDEX WORDs. volatile, vapor phase, postharvest, gray mold, Fragaria $\times$ ananassa

\begin{abstract}
Some plant-derived natural volatile compounds exhibit antifungal properties and may offer an opportunity to control the causes of postharvest spoilage without affecting quality of, or leaving a residue on, fresh produce. The natural wound volatile $(E)$-2-hexenal has exhibited significant antifungal activity in earlier studies, but effects on spore germination and mycelial growth have not been separated, nor has the inhibitory mode of action been determined. To determine the efficacy of $(E)$-2-hexenal for control of Botrytis cinerea Pers. ex Fr. spore germination and mycelial growth, and to examine the mode of action, in vitro and in vivo studies were performed. Under in vitro bioassay conditions, spore germination was more sensitive to the compound than was mycelial growth. Vapor from $10.3 \mu \mathrm{mol}$ of $(E)$-2-hexenal in a 120 -mL petri dish completely inhibited spore germination. However, $85.6 \mu \mathrm{mol}$ of $(E)$-2-hexenal was required to completely inhibit mycelial growth. Lower concentrations of the compound (5.4 and $10.3 \mu \mathrm{mol})$ significantly stimulated mycelial growth, especially when the volatile was added 2 days following inoculation. Mycelial growth did not occur as long as the vapor-phase concentration was $0.48 \mu \mathrm{mol} \cdot \mathrm{L}^{-1}$ or greater. Light microscopy analysis indicated that a high concentration of volatile compound dehydrated fungal hyphae and disrupted their cell walls and membranes. Exposure of $B$. cinerea-inoculated and non-inoculated strawberry (Fragaria xananassa Duch.) fruit in 1.1-L low-density polyethylene film-wrapped containers to vapor of $(E)$-2hexenal at 85.6 or $856 \mu \mathrm{mol}(10$ or $100 \mathrm{~mL}$, respectively) per container for durations of 1, 4, or 7 days during 7 days of storage at $2{ }^{\circ} \mathrm{C}$ promoted the incidence of $B$. cinerea during subsequent shelf storage at 20 to $22^{\circ} \mathrm{C}$. Loss of fruit fresh mass and fruit firmness during storage at $22^{\circ} \mathrm{C}$ was increased by $(E)$-2-hexenal treatment, but fruit total soluble solids, pH, titratable acidity, and color ( $L, C$, and $H$ values) were not affected. Thus, maintenance of a high vapor-phase level of $(E)$-hexenal, perhaps $>0.48$ $\mu \mathrm{mol} \cdot \mathrm{L}^{-1}$, may be necessary to inhibit mycelial growth and avoid enhancing postharvest mold problems, while significantly higher levels may be necessary to completely eliminate the pathogen.
\end{abstract}

Preharvest fungal diseases of strawberry fruit are usually controlled with bloom fungicide applications (Eckert and Ogawa, 1988; Powelson, 1960), but control is not always carried over into postharvest storage. The use of synthetic fungicides imposes selective pressure on pathogen populations and may result in predominance of fungicide-resistant strains (Beever and Parks, 1993; Elmer and Gaunt, 1994). Additionally, there is increasing concern among consumers and regulatory agencies concerning the health hazards of synthetic pesticide residues (Wilson and Wisniewski, 1989). Therefore, effective and safe means of postharvest pathogen control must be developed. Modified atmosphere storage can suppress postharvest pathogen development (El-Goorani and Sommer, 1981), but problems may develop following removal to warmer shelf storage. Irradiation may also reduce pathogen problems (Yu et al., 1995), but it has yet to be widely accepted by consumers (Marcotte, 1992).

Naturally occurring plant-derived volatiles with antifungal activity may provide an additional alternative for control of postharvest pathogens. These volatile compounds have been studied for their potential exploitation as inhibitors of postharvest spoilage

Received for publication 29 Oct. 1997 . Accepted for publication 28 Apr. 1998. The investigation reported in this paper (no. 97-11-55) is in connection with a project of the Kentucky Agricultural Experiment Station and is published with the approval of the director. This work was supported by USDA-NRI grant no. 94-37500-0553. The cost of publishing this paper was defrayed in part by the payment of page charges. Under postal regulations, this paper therefore must be hereby marked advertisement solely to indicate this fact.

'Research conducted while E. Fallik was on sabbatical at the University of Kentucky.

${ }^{2}$ To whom reprint requests should be sent. of several fruits (Archbold et al., 1997a, 1997b; Prasad and Stadelbacher, 1974; Song et al., 1996; Vaughn et al., 1993; Wilson et al., 1987). (E)-2-hexenal, a six-carbon aldehyde, is one of the most widespread and abundant volatile compounds in plant tissues (Hatanaka, 1993). Exposure of spores to vapor-phase concentrations of this and other compounds inhibited germ tube growth of postharvest decay-causing fungi (Anderson et al., 1994; HamiltonKemp et al., 1992), including $B$. cinerea, the causal agent of gray mold in many fruits and vegetables (Barkai-Golan, 1981). Many volatile compounds are produced and metabolized by fruit such as strawberry (Hamilton-Kemp et al., 1996; Nijssen et al., 1996), and may leave no residues after their use.

Although $(E)$-2-hexenal was found to affect $B$. cinerea spore germination in vitro (Anderson et al, 1994) and have significant antifungal activity on $B$. cinerea-inoculated strawberries (Archbold et al., 1997a, 1997b), there is no information on $(E)$-2-hexenal effects on mycelial growth in comparison to spore germination. This distinction may be important when fruit exhibit quiescent or incipient infections at the time of harvest and receive subsequent treatment with a volatile compound. In addition, some volatiles may stimulate fungal growth (French, 1985), although this has not been studied with $(E)$-2-hexenal on $B$. cinerea in vitro or in vivo. The inhibitory mode of action of $(E)$-2-hexenal and other volatile compounds is not known, but French (1985) summarized several possibilities for stimulatory responses. Therefore, the goals of this study were to evaluate the in vitro and in vivo efficacy of $(E)-2-$ hexenal in controlling $B$. cinerea spore germination and mycelial growth and to understand, in part, the mode of action of this compound. 


\section{Materials and Methods}

IN VITRO EXPERIMENTS. Botrytis cinerea was obtained from a diseased strawberry fruit. A culture was established via the single spore technique and maintained on potato dextrose agar (PDA). The effect of $(E)$-2-hexenal on spore germination and mycelial growth was tested in a bioassay system modified from that described by Hamilton-Kemp et al. (1992). Spore germination and mycelial growth tests were conducted on PDA poured directly into a 9-cm-diameter $(120-\mathrm{mL})$ glass petri dish. A 1-cm-diameter glass microbeaker was placed in the PDA to hold $1 \mathrm{~mL}$ of sterile deionized water with $10 \mathrm{~mL}$ of test solution. $(E)$-2-hexenal in various amounts in propylene glycol was prepared as described in Hamilton-Kemp et al. (1992). A spore suspension was prepared in sterile distilled water and $0.3 \mathrm{~g} \cdot \mathrm{L}^{-1}$ Tween 20 from a 14-d-old single conidium culture grown on PDA at $22^{\circ} \mathrm{C}$.

Aliquots $(80 \mu \mathrm{L})$ of the spore suspension $\left(10^{4}\right.$ spore $\left./ \mathrm{mL}\right)$ were streaked aseptically onto the PDA. The spores were exposed 10$\mu \mathrm{L}(E)$-2-hexenal/propylene solutions with 0 (control of propylene glycol only), $0.5,1.1,5.4$, and $10.3 \mu$ mol of the compound placed on $1 \mathrm{~mL}$ of water in the microbeaker. The petri dish was wrapped in Parafilm and germinating spores were counted after 24 and 48 $\mathrm{h}$ of incubation at $20^{\circ} \mathrm{C}$ as described previously (Fallik et al., 1993). The experiment was repeated four times, each with four replications of each treatment.

In a parallel experiment, $10 \mu \mathrm{L}$ of $(E)$-2-hexenal at $0,5.4,10.3$, and $47.3 \mu$ mol as well as $10 \mu \mathrm{L}$ of neat $(E)$-2-hexenal, or $85.6 \mu \mathrm{mol}$, was added directly to $1 \mathrm{~mL}$ water in a microbeaker and evaluated for effects on mycelial growth of $B$. cinerea. A 4-mm-diameter plug of mycelial mat from the periphery of a 14-d-old culture was placed at the center of the 9 -cm petri dish containing PDA medium. Additional dishes were set up without a plug of mycelial mat and with a plug but subsequently autoclaved. The volatile was added immediately after inoculation, when the dishes were at room temperature if autoclaved, or $2 \mathrm{~d}$ following inoculation, and the petri dish was wrapped in Parafilm. The additional dishes received only $10.3 \mu \mathrm{mol}$ of $(E)$-2-hexenal. Mycelial growth was determined by measuring the colony diameter every $24 \mathrm{~h}$ for $5 \mathrm{~d}$ at $20^{\circ} \mathrm{C}$. The experiments were repeated four times with four replications of each treatment in each trial, using fresh 14-d-old fungal culture in each experiment. Mycelial appearance was examined after a 5-d incubation using an Olympus BX-40 light microscope at 100 or $400 \times$ magnification.

To determine the vapor-phase concentration of the $(E)$-2-hexenal over time, $150-\mu \mathrm{L}$ samples of headspace vapor from the bioassay system were withdrawn through a rubber septum, which had been inserted in a 5.4- $\mathrm{mm}$ hole in the petri dish cover, using a gas-tight syringe (Hamilton, Reno, Nevada). Samples were injected into a Hewlett Packard 5890 gas chromatograph (GC) (Palo Alto, Calif.) equipped with a $0.53 \mathrm{~mm} \times 30-\mathrm{m} \mathrm{DB}$-wax (polyethylene glycol) column with a 1-mm film thickness (Supelco Inc., Bellefonte, Pa.). The operating conditions were as follows: injector; $220^{\circ} \mathrm{C}$; column oven, $50^{\circ} \mathrm{C}$ for $5 \mathrm{~min}$, then programmed at $3^{\circ} \mathrm{C} / \mathrm{min}$ to $110^{\circ} \mathrm{C}$; FID, $240^{\circ} \mathrm{C}$; He flow rate, $6 \mathrm{~mL} \cdot \mathrm{min}^{-1}$. The identification of $(E)$-2-hexenal in the headspace was confirmed by GC-MS using a Hewlett-Packard 5895 instrument as reported earlier (Hamilton-Kemp et al., 1996). The response factor for the compound on the GC was determined as in Hamilton-Kemp et al. (1992).

IN vivo EXPERIMENTS. 'Chandler' strawberry fruit were obtained from field plots not treated with fungicide and used the same day. Fruit were selected on the basis of uniform size, color, firmness, and freedom from evident defects or diseases. In 1996, fruit were inoculated by spraying them with a spore suspension of
B. cinerea at $10^{6} \mathrm{spores} / \mathrm{mL}$. Ten still-moistened fruit were placed inside a $250-\mathrm{mL}$ perforated plastic clamshell container. In 1997 , six noninoculated fruit were placed in a $150-\mathrm{mL}$ perforated clamshell container. Liquid (E)-2-hexenal was included at 0 (control), 85.6, or $856 \mu \mathrm{mol}$ ( 10 or $100 \mu \mathrm{L}$, respectively) of neat compound in a 10 $\mathrm{mL}$ glass vial within the container. Containers were loosely overwrapped and hermetically sealed in low density polyethylene film (film thickness $0.0021 \mu \mathrm{m}$, RESPIRE, Cincinnati, Ohio) for a total volume of $1.1 \mathrm{~L}$. Fruit were stored at $2{ }^{\circ} \mathrm{C}$ for $7 \mathrm{~d}$. In 1996 , the headspace vapor within the overwrapped container was sampled through the film using a gas-tight syringe and resealed with plastic adhesive tape on day 2 . The headspace sample was measured by $\mathrm{GC}$ as described above for the petri dish system. After 1 or $4 \mathrm{~d}$ vials with compound were removed from some containers, and the film was resealed. After $7 \mathrm{~d}$, all film and remaining vials with compound were removed. The containers were then stored at $20^{\circ} \mathrm{C}(1996)$ or 22 ${ }^{\circ} \mathrm{C}$ (1997). The number of infected fruit were determined at $8,9,10$, and $11 \mathrm{~d}$. Each treatment, or $(E)$-2-hexenal volume by duration of exposure, was replicated three times at one harvest date in 1996 and five times on each of two harvest dates in 1997.

FruIt Quality MEASUREments, 1997. For analysis of mass loss during the experiment, all containers were weighed at the start and after 7 and $10 \mathrm{~d}$ of storage. The percent mass loss was calculated for each container.

Two containers of six fruit from each treatment were removed from the experiment after 0,7 , and $10 \mathrm{~d}$ of storage for analysis of color and quality traits [total soluble solids (TSS), $\mathrm{pH}$, and titratable acidity (TA)]. All fruit were individually evaluated for color using a Minolta Chroma Meter (model CR-200; Osaka, Japan) calibrated with a standard white plate (CR-A43). The values for $L$, $\mathrm{C}$, and $\mathrm{H}$ were recorded for each fruit. The fruit were then placed into a sealed plastic bag and frozen. About $1.1 \mathrm{~kg}$ of the frozen fruit were removed and pureed in a Waring blender. The puree was squeezed through four layers of cheesecloth and 1 layer of Miracloth (Calbiochem, LaJolla, Calif.). The TSS content of the juice was determined using a refractometer (AOScientific Instruments, Keene, N.H.). The $\mathrm{pH}$ of the juice was determined with a Solution Analyzer (Amber Sciences Inc., Eugene, Ore.). The TA of the juice was determined by adding $5 \mathrm{~mL}$ of it to $95 \mathrm{~mL}$ of deionized water and titrating the solution to $\mathrm{pH} 7.0$ with $1.1 \mathrm{M} \mathrm{NaOH}$ water. The TA is reported as percentage citric acid. The analyses were performed with fruit from the two 1997 harvest dates.

To determine if $(E)$-2-hexenal treatment affects fruit firmness, a single container of fruit from two treatments, no volatile compound (control) or $(E)$-2-hexenal at $856 \mu \mathrm{mol}(100 \mu \mathrm{L})$, were removed after $0,3,7,9$, and $11 \mathrm{~d}$ of storage. Fruit firmness was measured on each of the six fruit within the container using a Chatillon Force Gauge (model DFM 10; John Chatillon and Sons, Inc., Greensboro, N.C.) mounted on a model LTC test stand and equipped with a $6.3-\mathrm{mm}$-diameter cone tip. The maximum force required for the cone tip to fully penetrate the fruit surface with slow manual advancement, with the fruit lying horizontally on the stage and the cone tip positioned on the fruit shoulder, was recorded for each fruit. The experiment was performed with fruit from both harvest dates in 1997.

Data from studies on mycelial growth were analyzed by analysis of variance (ANOVA) (SAS, Cary, N.C.) with treatment means compared using an overall LSD at $P=0.5$. Percent infection for each container in the storage studies was calculated and, along with fruit quality data, was also subjected to ANOVA. The storage data from 1996 and 1997 were combined for ANOVA, blocking by year. The main effects of liquid $(E)$-2-hexenal volume and duration of treatment, trends within main effects, and their interactions on 


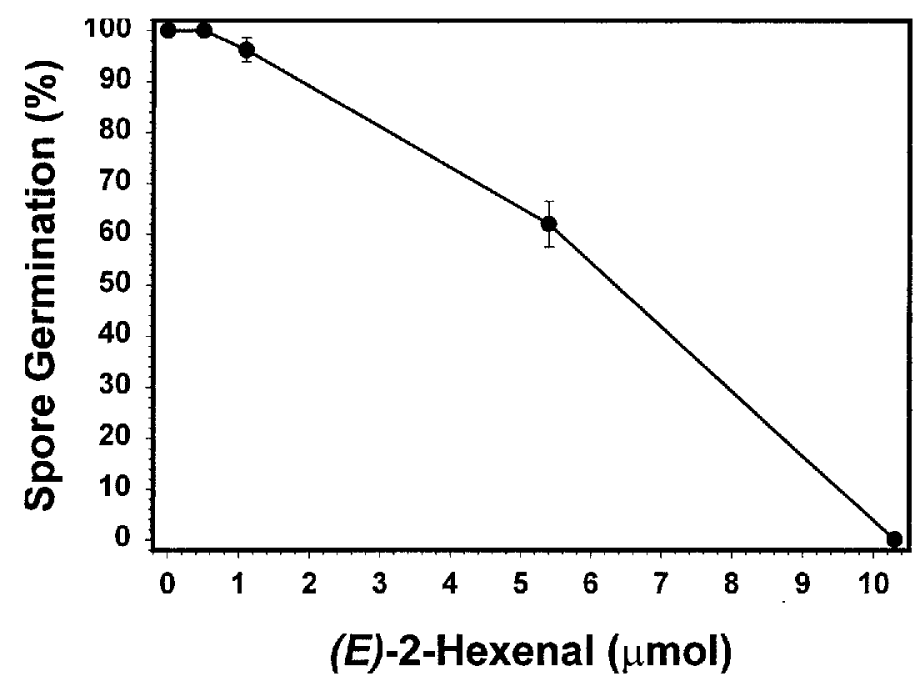

Fig. 1. The percentage of Botrytis cinerea spore germination in vitro after exposure to $(E)$-2-hexenal quantities in propylene glycol for $24 \mathrm{~h}$. Values are means of four cxperiments, four replications per treatment in each experiment, $\pm \mathrm{sE}$.

percent $B$. cinerea infection and fruit quality traits were not significant, although a single degree of freedom orthogonal contrast for control versus $(E)$-2-hexenal treatment was included in the analyses and is presented if significant at $P \leq 0.5$.

\section{Results}

IN VITRO EXPERIMENTS. The percentage spore germination was inversely proportional to $(E)$-2-hexenal quantity after $24 \mathrm{~h}$ (Fig. 1). A slight inhibition was evident with $1.1 \mu \mathrm{mol}(E)$-2-hexenal, while $10.3 \mu \mathrm{mol}$ of compound completely inhibited spore germination. Treatment effects persisted through $48 \mathrm{~h}$ (data not shown).

Mycelial growth of $B$. cinerea was completely inhibited by vapor from $85.6 \mu \mathrm{mol}(E)$-2-hexenal when the compound was added immediately after inoculation (Fig. 2A). No mycelial regrowth was observed following removal of the compound from the dishes after $72 \mathrm{~h}$ of exposure (data not shown). Adding $85.6 \mu \mathrm{mol}$ $(E)$-2-hexenal $2 \mathrm{~d}$ after inoculation reduced colony diameter for about $2 \mathrm{~d}$, but then a slow regrowth was subsequently observed (Fig. 2B). The decrease in diameter of the culture appeared to be due to the death and degradation of the mycelia as subsequently shown by microscopic examination. A $47.3 \mu \mathrm{mol}(E)$-2-hexenal quantity also significantly inhibited fungal growth, especially when the compound was added immediately after inoculation (Fig. 2A).

In contrast to the response to $85.6 \mathrm{mmol}(E)$-2-hexenal, 5.4 $\mu \mathrm{mol}$ significantly enhanced mycelial growth compared with the control (no $(E)$-2-hexenal added to the water in the microbeaker) when added either immediately after inoculation or $2 \mathrm{~d}$ later (Fig. $2 \mathrm{~A}$ and $\mathrm{B}$ ). This enhancement was noted at 96 and $120 \mathrm{~h}$. A 10.3 $\mu$ mol quantity of the compound enhanced mycelial growth after $120 \mathrm{~h}$ only when added $2 \mathrm{~d}$ after inoculation (Fig. 2B).

Light microscopy revealed severe membrane and cell wall damage as well as deterioration and nonlinear growth of the hyphae when the fungus was exposed to $85.6 \mu \mathrm{mol}(E)$-2-hexenal (Fig. $3 \mathrm{~B}$ and $\mathrm{C}$ ). In contrast, untreated hyphal tips had intact membranes and cell walls (Fig. 3A).

The maximum vapor-phase concentration in the petri dishes was observed at the first measurement time of $3 \mathrm{~h}$, and concentration subsequently decreased during the incubation period (Table 1, Fig. 4). Once mycelial growth was observed, indicated by underlines, the vapor-phase concentration had declined markedly. No growth was observed when the vapor-phase concentration was equal to or greater than $0.48 \mu \mathrm{mol} \cdot \mathrm{L}^{-1}$. However, at concentrations of $0.16 \mu \mathrm{mol} \cdot \mathrm{L}^{-1}$ and below, mycelial growth was observed in the bioassay system. The presence of a growing $B$. cinerea colony reduced headspace concentration considerably compared with plates containing no mycelia and those with mycelia killed by autoclaving (Fig. 4).

IN VIVO EXPERIMENTS. By the end of the storage-shelf life period, control fruit exhibited $>90 \%$ infection (Fig. 5 ). However, preliminary studies indicated no effect of inoculation on the severity or rate of development of $B$. cinerea (data not shown). Exposing $B$. cinerea-inoculated strawberry fruit to the vapor of neat $(E)-2$ hexenal enhanced fruit infection after 9 and $10 \mathrm{~d}$ of storage compared with controls that were not exposed to the volatile compound (Fig. 5). There were no significant main effects of liquid volume or duration of exposure, or their interaction, on the incidence of $B$. cinerea. The vapor-phase concentration after $2 \mathrm{~d}$ of storage was $0.06 \pm 0.01$ and $0.37 \pm 0.01 \mu \mathrm{mol} \cdot \mathrm{L}^{-1}$ for 85.6 and 856 $\mu \mathrm{mol}$ neat $(E)$-2-hexenal, respectively.

Use of $(E)$-2-hexenal increased the loss of fruit mass compared to controls after $7 \mathrm{~d}$ in cold storage and 3 more $\mathrm{d}$ at $22^{\circ} \mathrm{C}$ (Fig. 6). Other aspects of fruit quality, including TSS, pH, TA, and color $(\mathrm{L}$, $\mathrm{C}$, and $\mathrm{H}$ values), were not affected by $(E)-2$-hexenal treatment,

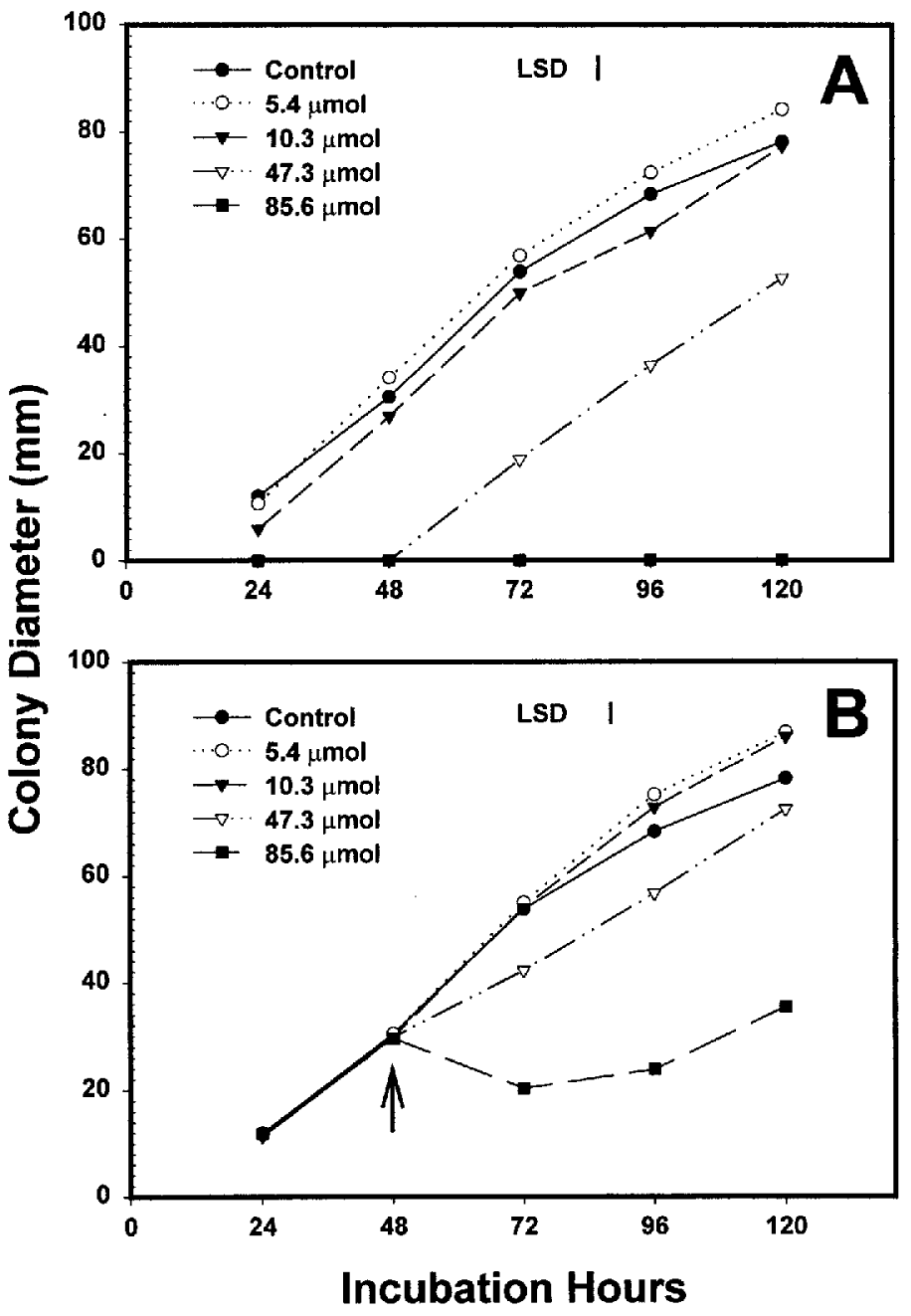

Fig. 2. Mycelial growth (colony diameter in $\mathrm{mm}$ ) of Botrytis cinerea after exposure to $(E)$-2-hexenal at different quantities in propylene glycol, except that at 85.6 $\mu \mathrm{mol}(E)$-2-hexenal alone was used. (A) The compound was added immediately after inoculation. (B) The compound was added $48 \mathrm{~h}$ following inoculation. Arrow indicates the time of addition of volatile. An overall $\mathrm{s}$ SD at $P \leq 0.5$ is shown for means comparison. 


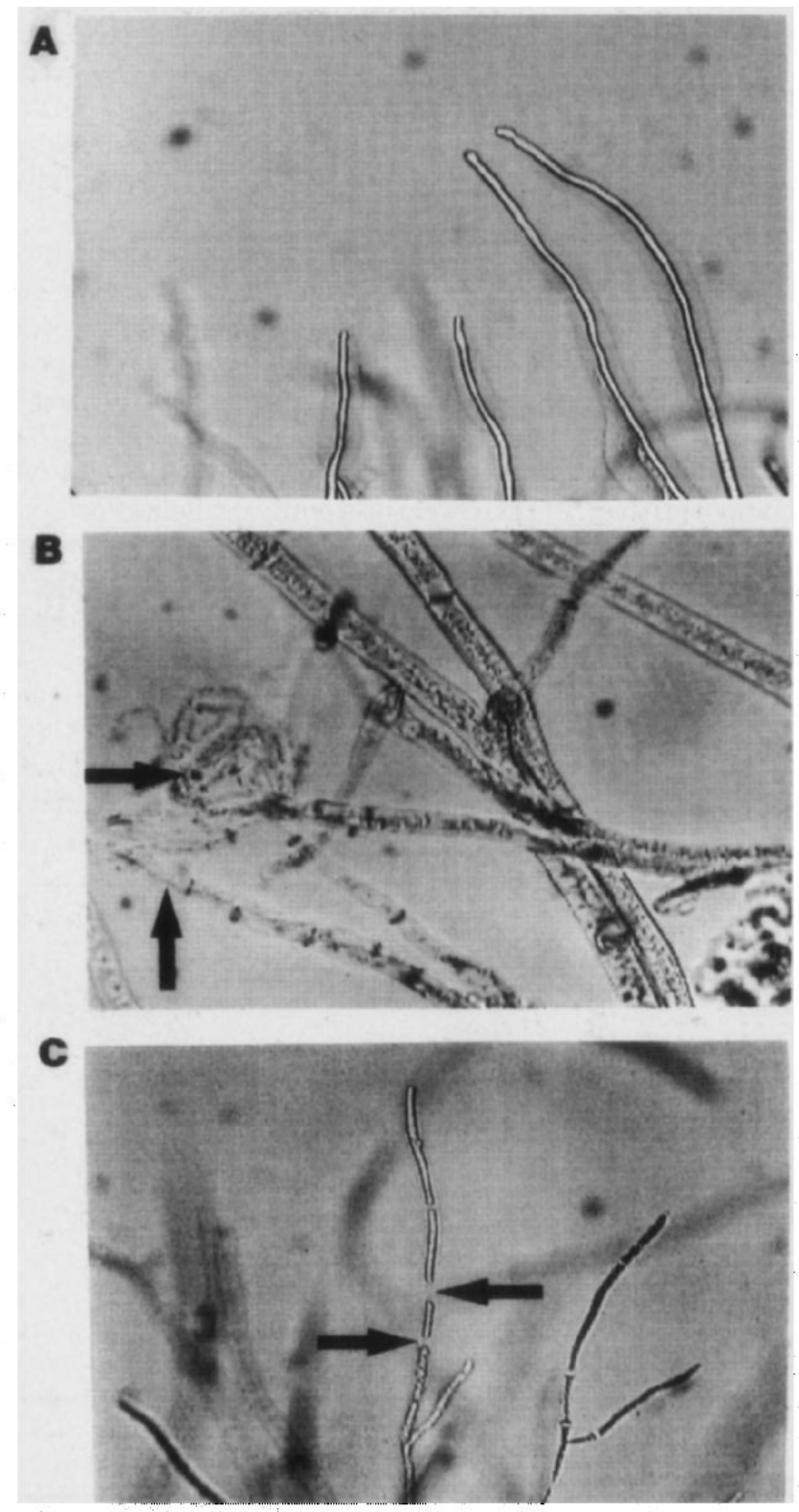

Fig.3.(A)Control hyphal tips of Botrytis cinerea $(100 \times)$.(B) Myceliaexposed to $85.6 \mu \mathrm{mol}$ (E)-2-hexenal. Arrows show desiccaled and nonlinear mycelia $(400 \times)$. (C) Botrytis cinerea hyphal tips exposed to $85.6 \mu \mathrm{mol}(E)$-2-hexenal. Arrows show damage in cell wall $(100 \times)$. Pictures were taken $5 \mathrm{~d}$ after incubation at $20^{\circ} \mathrm{C}$. although control and treatment values are presented for comparison (Table 2). Fruit firmness declincd in all fruit during storage at $22^{\circ} \mathrm{C}$, and it was reduced by $(E)$-2-hexenal treatment from 7 to 11 d of storage (Fig. 7).

\section{Discussion}

Botrytis cinerea sporc germination was more sensitive to $(E)$ 2-hexenal concentration than was mycelial growth (Figs. 1,2). Although no stimulation of spore germination was observed at the concentrations tested in this study, treatment with $(E)$-2-hexenal resulted in stimulation and inhibition of $B$. cinerea mycelial growth in vitro. These results were dependent on the amount of volatile compound and, therefore, the vapor-phase quantities inside the test system. The higher test quantities of the compound inhibited spore germination and mycelial growth. However, lower vapor-phase concentrations enhanced mycelial growth but not spore germination. Several studies on fungal pathogens that cause rust and other diseases show that several volatile compounds stimulate spore germination (French, 1985, 1990). Low concentrations of aldchydes such as hexanal also appeared to stimulate germ tube growth of fungal pathogens (Hamilton-Kemp et al., 1992). The inhibitory effect of $(E)$-2-hexenal against $B$. cinerea at higher vapor-phase concentrations may be due, in part, to the severe damage to the fungal membranes and cell walls which resulted in collapse and deterioration of hyphae (Fig. 3). This may be the result of $(E)$-2-hexenal interaction with protein sulfhydryl and amino groups of B. cinerea (Andersen et al., 1994). However, the cause of stimulation is not known although French (1985) speculates about possible reasons.

The $B$. cinerea colonies removed the compound from the vapor phase (Fig. 4), causing the sharp decline in the vapor-phase concentration in the petri dishes at $72 \mathrm{~h}$ (Table 1 ). The vapor-phase concentration after $24 \mathrm{~h}$ in the spore germination bioassays would be considerably higher than that in the colony bioassays as Andersen et al. (1994) have shown, comparable to the noninoculated dishes in Fig. 4, contributing to the greater effectiveness of low levels of $(E)$-2-hexenal against the spores. Botrytis cinerea mycelia might have formed metabolic products from $(E)$-2-hexenal contributing to fungal growth stimulation in some manner, but none were detected in the present study.

It is unlikely that there were humidity differences among treatments that would account for the $(E)$-2-hexenal stimulation of mycelial growth. Each dish contained a microbeaker with $1 \mathrm{~mL}$ of water and only $10 \mu \mathrm{L}$ of $(E)$-2-hexenal in propylene glycol, both

Table 1. Vapor-phase concentrations of (E)-2-hexenal vapor in the petri dish bioassay of Botrytis cinerea mycelial growth at different $(E)$-2-hexenal amounts per dish (means of two experiments $\pm \mathrm{sE}$ ). Underlined values indicate mycelial growth was observed and measured as shown in Fig. 2.

\begin{tabular}{|c|c|c|c|c|}
\hline \multirow{2}{*}{$\begin{array}{l}\text { Time }(\mathrm{h}) \text { after } \\
\text { adding volatile }\end{array}$} & \multicolumn{4}{|c|}{$\begin{array}{l}\text { Vapor-phase concentration }\left(\mu \mathrm{mol} \cdot \mathrm{L}^{-1}\right) \\
\text { after adding liquid }(E) \text {-2-hexenal }(\mu \mathrm{mol})\end{array}$} \\
\hline & 5.4 & 10.3 & 47.3 & 85.6 \\
\hline & \multicolumn{4}{|c|}{ Added immediately after inoculation } \\
\hline 3 & $0.19 \pm 0.02$ & $0.39 \pm 0.02$ & $1.39 \pm 0.03$ & $5.12 \pm 0.24$ \\
\hline 24 & $\underline{0.02 \pm 0.01}$ & $0.04 \pm 0.01$ & $0.67 \pm 0.02$ & $3.76 \pm 0.13$ \\
\hline 48 & $\overline{0.01 \pm 0.01}$ & $0.02 \pm 0.01$ & $0.48 \pm 0.01$ & $3.00 \pm 0.06$ \\
\hline 72 & $0.02 \pm 0.01$ & $0.03 \pm 0.01$ & $0.06 \pm 0.01$ & $2.78 \pm 0.04$ \\
\hline \multirow[t]{2}{*}{96} & $0.01 \pm 0.01$ & $0.02 \pm 0.01$ & $\underline{0.03 \pm 0.01}$ & $2.41 \pm 0.03$ \\
\hline & \multicolumn{4}{|c|}{ Added $48 \mathrm{~h}$ following inoculation } \\
\hline 3 & $0.21 \pm 0.03$ & $0.34 \pm 0.01$ & $1.84 \pm 0.02$ & $4.94 \pm 0.03$ \\
\hline 24 & $\underline{0.02 \pm 0.01}$ & $0.04 \pm 0.01$ & $\underline{0.04 \pm 0.01}$ & $0.73 \pm 0.04$ \\
\hline 48 & $0.01 \pm 0.01$ & $\underline{0.01 \pm 0.01}$ & $\overline{0.03 \pm 0.01}$ & $\underline{0.16 \pm 0.01}$ \\
\hline
\end{tabular}




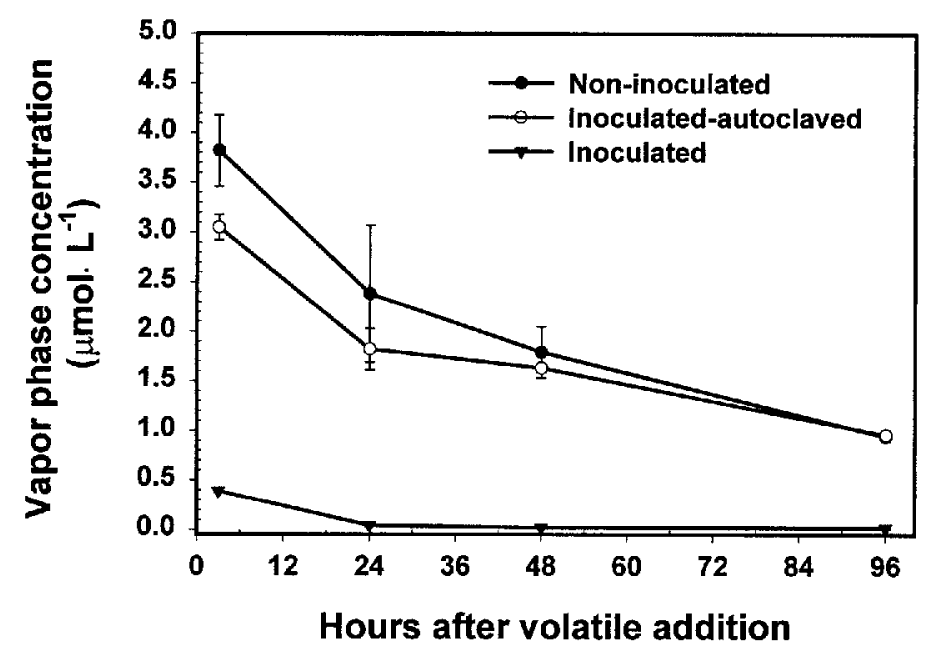

Fig. 4. Vapor-phase concentration of (E)-2-hexenal in non-inoculated petri dishes, in dishes inoculated with plugs of mycelial mat of Botrytis cinerea and subsequently autoclaved, and in inoculated dishes. (E)-2-hexcnal was supplied at $10.3 \mu \mathrm{mol}$ Means \pm SE of three dishes measured at each time.

of which are hygroscopic. The water volume in the microbeaker did not change appreciably during the bioassays; thus it could have humidified the air equally in all treatments.

The vapor-phase concentrations of $(E)$-2-hexenal in the strawberry storage containers in cold storage were low and were followed by in vivo stimulation during warmer shelf storage (Fig. 5). These vapor-phase concentrations, 0.06 and $0.37 \mu \mathrm{mol} \cdot \mathrm{L}^{-1}$, respectively, were less than the level needed to inhibit mycelial growth in the in vitro studies. Thus, the increase in the percentage of infected strawberry fruit at 9 and $10 \mathrm{~d}$ of storage might be explained by an insufficiently high vapor-phase concentration inside the overwrapped containers. Quiescent infections may have been stimulated while the fruit were in cold storage, leading to the more rapid development of infection upon removal of the fruit to the warmer storage environment. Continuing metabolism of $(E)$ 2-hexenal by strawberry fruit from days 2 to 7 of cold storage (Archbold et al., 1997a; Hamilton-Kemp et al., 1996) and loss of compound through the LDPE film (Song et al., 1996) likely resulted in the low vapor-phase concentration. In single fruit bioassays, mold development on strawberry was inhibited by similar vapor-phase levels if the chemical remained with the fruit during the warmer shelf storage period (Archbold et al., 1997a). In the present studies, the compound was removed from the containers when the fruit were transferred from cold storage. Also, strawberry fruit form additional volatile alcohol and ester metabolites when treated with $(E)$-2-hexenal as has been reported in detail (Hamilton-Kempetal., 1996), and these compounds have not been studied to determine their potential for $B$. cinerea growth stimulation in vitro or in vivo.

A variety of application strategies and vapor-phase concentrations have been used in studies indicating that selected natural volatile compounds inhibit postharvest pathogens in vivo (Archbold et al., 1997a, 1997b; Caccioni et al., 1995; Song et al., 1996; Vaughn et al., 1993). While the primary goal of this project is to develop methods using volatile compounds to control $B$. cinerea and other pathogens, the in vitro results clearly indicated that inappropriate vapor-phase levels might exacerbate the problem. The most effective technique to control fungal development on strawberry with a compound such as $(E)$-2-hexenal may be fumigation with a relatively high volatile concentration for a short period of time immediately after harvest. The vapor-phase concen- tration would need to be high enough to eliminate quiescent infections however. It is possible that the pathogenicity of the $B$. cinerea isolates used for fruit inoculation in 1996 was less than that of the field-derived inoculum since inoculation failed to increase the rate of mold development (data not shown). However, spores can be controlled with much lower vapor-phase levels than mycelia, so nongerminated inoculum may have been inhibited by $(E)$-2-hexenal both years, leaving only quiescent infections which appear to require higher vapor-phase concentrations than attained in this work for effective inhibition. Eliminating the quiescent infections may be difficult to achieve, because mycelial growth was not completely inhibited in vitro when $(E)$-2-hexenal at $85.6 \mu \mathrm{mol}$ was introduced 2 $\mathrm{d}$ after inoculation of the media. The established $B$. cinerea colony was able to absorb a significant amount of the volatile compound within $24 \mathrm{~h}$, as compared with introduction of the compound at the time of inoculation (Table 1). That fact combined with the ability

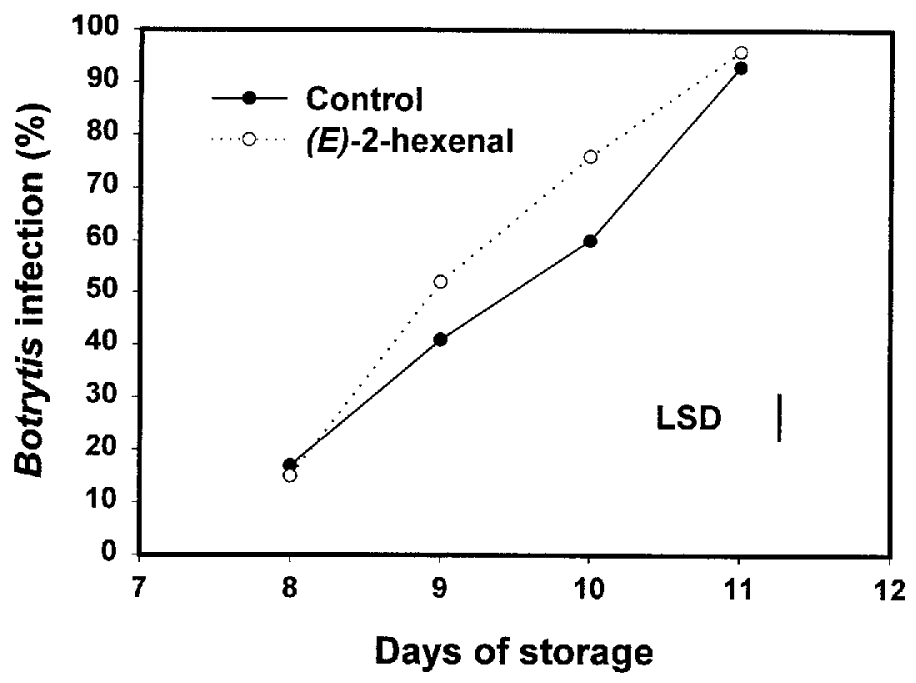

Fig. 5. The percentage of Botrytis cinerea infection on 'Chandler' strawberry fruit after removal from cold storage as affected by exposure to 85.6 or $856 \mathrm{mmol}(10$ or $100 \mathrm{~mL}$, respectively) of neat $(E)$-2-hexenal per $1.1 \mathrm{~L}$ of overwrapped container volume during $7 \mathrm{~d}$ of cold storage. Mean values are across $(E)-2-$ hexenal treatments. An overall LSD at $P \leq 0.5$ is shown for means comparison.

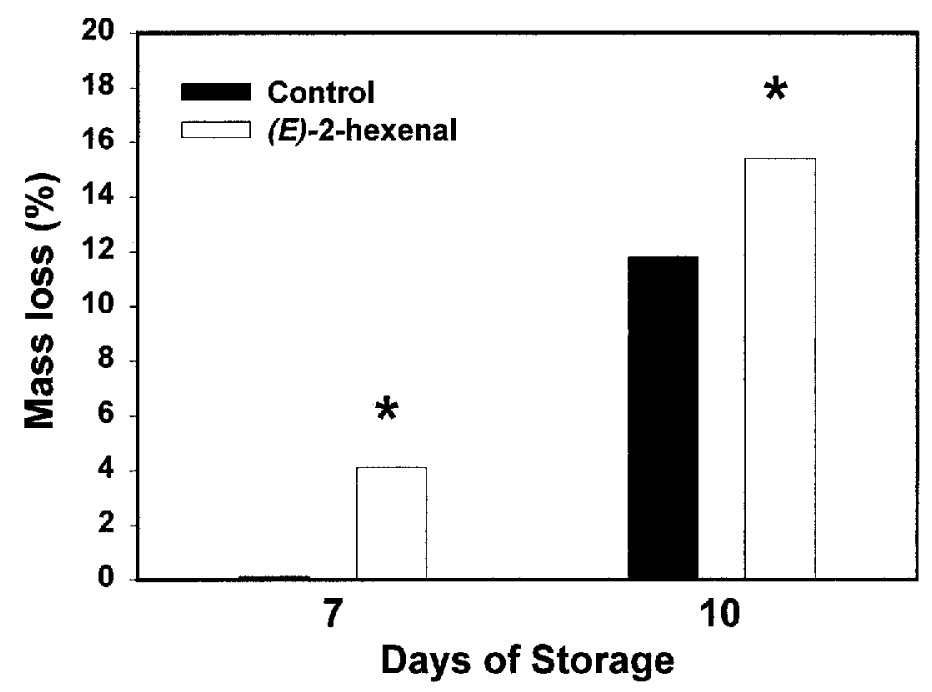

Fig. 6. Loss of 'Chandler' strawberry fruit mass as affected by exposure to 85.6 or $856 \mu \mathrm{mol}(10$ or $100 \mu \mathrm{L}$, respectively) of neat $(E)$-2-hexenal per 1.1-L overwrapped container volume. Fruit were stored for $7 \mathrm{~d}$ at $2^{\circ} \mathrm{C}$, and an additional $3 \mathrm{~d}$ at $22^{\circ} \mathrm{C}$. Mean values across all $(E)$-2-hexenal treatments that are significantly different from the control by a single degree of freedom orthogonal contrast at $P \leq 0.5$ are indicated by an asterisk (*). 
Table 2. Fruit quality traits of 'Chandler' strawberry following treatment with 85.6 and $856 \mu \mathrm{mol}(10$ and $100 \mu \mathrm{L}$, respectively) (E)-2-hexenal during cold storage at $4{ }^{\circ} \mathrm{C}$ for $7 \mathrm{~d}$ and subsequent $22^{\circ} \mathrm{C}$ storage. Data are presented as mean \pm standard error of the mean, $\mathrm{n}=4$ (control) or $36((E)$-2-hexenal) for total soluble solids, $\mathrm{pH}$, and titratable acidity, and $\mathrm{n}=24$ (control) or 216 $((E)$-2-hexenal) for color parameters.

\begin{tabular}{|c|c|c|c|c|}
\hline \multirow[b]{2}{*}{ Quality trait } & \multirow[b]{2}{*}{ Treatment } & \multicolumn{3}{|c|}{ Days of storage } \\
\hline & & 0 & 7 & 11 \\
\hline \multirow[t]{2}{*}{ Total soluble solids $(\%)$} & Control & $7.0 \pm 5.4$ & $7.0 \pm 0.2$ & $4.9 \pm 0.6$ \\
\hline & (E)-2-hexenal & & $6.2 \pm 0.6$ & $4.6 \pm 1.1$ \\
\hline \multirow[t]{2}{*}{$\mathrm{pH}$} & Control & $2.9 \pm 1.1$ & $2.9 \pm 1.1$ & $2.9 \pm 1.1$ \\
\hline & (E)-2-hexenal & & $3.0 \pm 1.1$ & $2.9 \pm 1.1$ \\
\hline \multirow[t]{2}{*}{ Titratable acidity (as \% citric acid) } & Control & $2.9 \pm 1.1$ & $3.0 \pm 1.1$ & $2.5 \pm 1.1$ \\
\hline & (E)-2-hexenal & & $2.9 \pm 1.1$ & $2.9 \pm 1.1$ \\
\hline \multicolumn{5}{|l|}{ Color } \\
\hline \multirow[t]{2}{*}{$\mathrm{L}$} & Control & $36 \pm 3$ & $33 \pm 3$ & $33 \pm 4$ \\
\hline & (E)-2-hexenal & & $33 \pm 1$ & $32 \pm 1$ \\
\hline \multirow[t]{2}{*}{$\mathrm{C}$} & Control & $39 \pm 3$ & $40 \pm 6$ & $28 \pm 4$ \\
\hline & (E)-2-hexenal & & $40 \pm 1$ & $24 \pm 3$ \\
\hline \multirow[t]{2}{*}{$\mathbf{H}$} & Control & $28 \pm 4$ & $27 \pm 4$ & $30 \pm 3$ \\
\hline & (E)-2-hexenal & & $26 \pm 1$ & $34 \pm 2$ \\
\hline
\end{tabular}

of the strawberry fruit to metabolize the compound may make it difficult to maintain an adequately high vapor-phase concentration during postharvest storage.

A brief treatment with a high vapor-phase level of $(E)-2$ hexenal might also reduce its adverse impact on fruit firmness and mass loss. Although other measured quality traits were not affected by the volatile compound, all problems must be minimized. These deleterious effects are significant concerns for the commercial use of $(E)$-2-hexenal and related natural volatile compounds on strawberry. Softer $(E)$-2-hexenal-treated fruit may be more susceptible to fungal attack. Loss of fruit fresh mass was increased by exposure to $(E)$-2-hexenal, and this moisture loss may also have contributed to the stimulation of mold development by increasing the humidity at the fruit-fungal interface. Strawberry absorbed and metabolized more $(E)$-2-hexenal than blackberry or grape (Archbold, et al., 1997a), so it may have a greater physiological response to volatile compound application than other species.

The putative advantages to using volatiles for fumigation to control postharvest decay development are due to their antimicro-

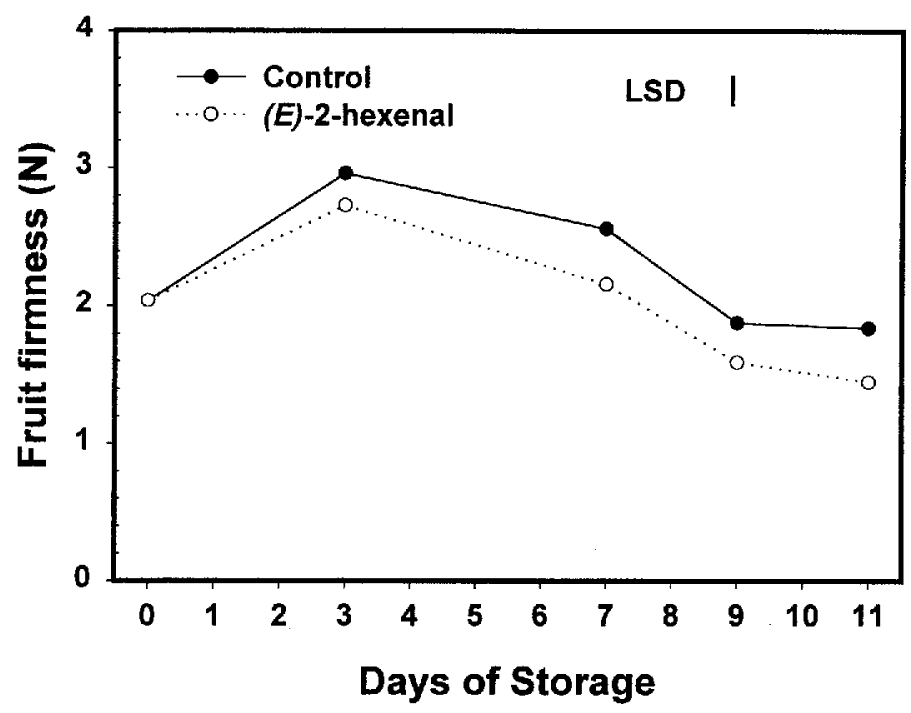

Fig. 7. Firmness in Newtons (N) of 'Chandler' strawberry fruit during $7 \mathrm{~d}$ of storage at $2{ }^{\circ} \mathrm{C}$ and after removal to storage at $22^{\circ} \mathrm{C}$ as affected by exposure to $856 \mu \mathrm{mol}$ $(100 \mu \mathrm{L})$ neat $(E)$-2-hexenal per overwrapped container volume. An overall LSD at $P \leq 0.5$ is shown for means comparison. bial properties and natural origin. Their volatility and metabolism may reduce the problems with residues. Thus, they are promising candidates for postharvest decay control, especially in fresh commodities to which the application of synthetic fungicides is banned. The eventual use of natural volatile compounds as antifungal fumigants could expand the market potential of high-quality fresh produce to distant markets. However, if natural volatile compounds such as $(E)$-2-hexenal exhibit both the ability to inhibit and stimulate fungal pathogens, establishing the minimum effective antifungal levels and adhering to those or greater levels, yet avoiding adverse effects on fruit quality, will be critical to their commercial acceptance.

\section{Literature Cited}

Andersen, R.A., T.R. Hamilton-Kemp, D.F.Hildebrand,C.T. McCracken, Jr., R.W. Collins, and P.D. Fleming. 1994. Structure-antifungal activity relationships among volatile $\mathrm{C}_{6}$ and $\mathrm{C}_{4}$ aliphatic aldehydes, ketones, and alcohols. J. Agr. Food Chem. 42:1563-1568.

Archbold, D.D., T.R. Hamilton-Kemp, M.M. Barth, and B.E. Langlois. 1997a. Identifying natural volatile compounds which control gray mold (Botrytis cinerea) during postharvest storage of strawberry, blackberry, and grape. J. Agr. Food Chem. 45:4032-4037.

Archbold, D.D., T.R. Hamilton-Kemp, B.E. Langlois, and M.M. Barth. 1997b. Natural volatile compounds control Botrytis on strawberry fruit. Acta Hort. 439:923-930.

Barkai-Golan, R. 1981. An annotated check-list of fungi causing postharvest diseases of fruits and vegetables in Israel. Agr. Res. Org., Bet Dagan, Israel, Spec. Publ. No. 194.

Beever, R.E. and S.L. Parks. 1993. Mating behaviour and genetics of fungicide resistance of Botrytis cinerea in New Zealand. N.Z. J. Crop Hort. Sci. 21:303-310.

Caccioni, D.R.L., G. Tonini, and M. Guizzardi. 1995. Antifungal activity of stone fruit aroma compounds against Monilinia laxa (Aderh. et Ruhl.) Honey and Rhizopus stolonifer (Ehrenb.): In vivo trials. J. Plant Dis. Protection 102:518-525.

Eckert, J.W. and J.M. Ogawa. 1988. The chemical control of postharvest diseases: Deciduous fruits, berries, vegetables and root/tuber crops. Annu. Rev. Phytopathol. 26:433-69.

El-Goorani, M.A. and N.F. Sommer. 1981. Effects of modified atmospheres on postharvest pathogens of fruits and vegetables. Hort. Rev. $3: 412-467$

Elmer, P.A.G. and R.E. Gaunt. 1994. The biological characteristics of dicarboximide-resistant isolates of Monilinia fructicola from New Zealand stone-fruit orchards. Plant Pathol. 43:130-137. 
Fallik, E., J. Klein, S. Grinberg, E. Lomaniec, S. Lurie, and A. Lalazar. 1993. Effect of postharvest heat treatment of tomatoes on fruit ripening and decay caused by Botrytis cinerea. Plant Dis. 77:985-988.

French, R.C. 1985. The bioregulatory action of flavor compounds on fungal spores and other propagules. Annu. Rev. Phytopathol. 23:179-199.

French, R.C. 1990. Stimulation of germination of teliospores of Puccinia punctiformis by nonyl, decyl and dodecyl isothiocyanates and related volatile compounds. J. Agr. Food Chem. 38:1604-1607.

Hamilton-Kemp, T.R., D.D. Archbold, J.H. Loughrin, R.W. Collins, and M.E. Byers. 1996. Metabolism of natural volatile compounds by strawberry fruit. J. Agr. Food Chem. 44:2802-2805.

Hamilton-Kemp, T.R., C.T. McCracken, Jr., J.H. Loughrin, R.A. Andersen, and D.F. Hildebrand. 1992. Effects of some natural volatile compounds on the pathogenic fungi Alternaria alternata and Botrytis cinerea. J. Chem. Ecol. 18:1083-1091.

Hatanaka, A. 1993. The biogeneration of green odour by green leaves. Phytochemistry 34:1201-1218.

Marcotte, M. 1992. Irradiated strawberries enter the U.S. market. Food Technol. 46(5):80-86.

Nijssen, C.M., C.A. Visscher, H. Maarse, L.C. Willemsens, and M.H. Boehms. 1996. Volatile compounds in food. 7th ed. TNO Nutr. Food
Res. Inst., The Netherlands.

Powelson, R.L. 1960. The initiation of strawberry fruit rot caused by Botrytis cinerea. Phytopathology 50:491-494.

Prasad, K. and G.J. Stadelbacher. 1974. Effect of acetaldehyde vapor on postharvest decay and market quality of fresh strawberries. Phytopathology 64:948-951.

Song, J., R. Leepipattanawit, W. Deng, and R.M. Beaudry. 1996. Hexanal vapor is a natural, metabolizable fungicide: Inhibition of fungal activity and enhancement of aroma biosynthesis in apple slices. J. Amer. Soc. Hort. Sci. 121:937-942.

Vaughn, S.F., G.F. Spencer, and B.S. Shasha. 1993. Volatile compounds from raspberry and strawberry fruit inhibit postharvest decay fungi. J. Food Sci. 58:793-796.

Wilson, C.L., J.D. Franklin, and B.E. Otto. 1987. Fruit volatiles inhibitory to Monilinia fructicola and Botrytis cinerea. Plant Dis. 71:316-319.

Wilson, C.L. and M.E. Wisniewski. 1989. Biological control of postharvest diseases of fruits and vegetables: An emerging technology. Annu. Rev. Phytopathol. 27:425-441.

Yu, L., C.A. Reitmeyer, M.L. Gleason, G.R. Nonnecke, D.G. Olson, and R.J. Gladon. 1995. Quality of electron beam irradiated strawberries. J. Food Sci. 60:1084-1087. 